\title{
Contents continued from outside back cover
}

Development of a larval diet for the South American fruit fly Anastrepha fraterculus

(Diptera: Tephritidae)

M.T. Vera, A. Oviedo, S. Abraham, M.J. Ruiz, M. Mendoza, C.L. Chang and E. Willink

Morphometric trait differentiation between a wild and a mass-reared population of Anastrepha fraterculus (Diptera: Tephritidae)

P.V. Gómez Cendra, D.F. Segura, A.C. Alberti and J.C. Vilardi

S82

A liquid larval diet for rearing Bactrocera invadens and Ceratitis fasciventris

(Diptera: Tephritidae)

S. Ekesi, S.A. Mohamed and C.L. Chang

S90

Artificial rearing of the peach fruit fly Bactrocera zonata (Diptera: Tephritidae)

P. Sookar, M. Alleck, N. Ahseek, S. Permalloo, S. Bhagwant and C.L. Chang

Rearing of Bactrocera zonata (Diptera: Tephritidae) for parasitoids production and managing techniques for fruit flies in mango orchards

S.M.M. Shah, N. Ahmad, M. Sarwar and M. Tofique

Improving olive fruit fly Bactrocera oleae (Diptera: Tephritidae) adult and larval artificial diets, microflora associated with the fly and evaluation of a transgenic olive fruit fly strain P. Rempoulakis, I. Dimou, A. Chrysargyris and A.P. Economopoulos

Effect of the symbiont Candidatus Erwinia dacicola on mating success of the olive fly Bactrocera oleae (Diptera: Tephritidae)

A.M. Estes, D.F. Segura, A. Jessup, V. Wornoayporn and E.A. Pierson

Demographic and quality control parameters of laboratory and wild Anastrepha striata

(Diptera: Tephritidae)

E. Hernández, J.P. Rivera, M. Aceituno-Medina, D. Orozco-Dávila and J. Toledo

Protein requirements of the adult Ethiopian fruit fly Dacus ciliatus

E. Nemny-Lavy and D. Nestel

Basic biology and artificial rearing of Bactrocera pyrifoliae (Diptera: Tephritidae), a pest of peaches and plums in northern Vietnam

L.D. Khanh, N.T.T. Hien, V.T. Trang, T.T. Toan and J. Rull 


\title{
INTERNATIONAL JOURNAL OF TROPICAL INSECT SCIENCE
}

\author{
Volume 34 Number S1 November 2014
}

\section{Introduction}

Development and improvement of rearing techniques for fruit flies (Diptera: Tephritidae) of economic importance

C. Cáceres, J. Hendrichs and M.J.B. Vreysen

\section{Research Papers}

Generic larval diet for mass-rearing three species of Anastrepha (Diptera: Tephritidae)

E. Hernández, J.P. Rivera and T. Artiaga-López

Anastrepha obliqua (Diptera: Tephritidae) mass-rearing: effect of relaxed colony management D. Orozco-Dávila, T. Artiaga-López, M. Del Refugio Hernández, J. Dominguez and E. Hernández

Improved mating performance of male Anastrepha ludens (Diptera: Tephritidae) irradiated at low doses for release in sterile insect technique programmes

J. Rull, J. Arredondo and F. Diaz-Fleischer

An evaluation of outcrossing to improve mass-reared strains of the Queensland fruit

fly Bactrocera tryoni

A.S. Gilchrist and A.W. Meats

Improvements in mass-rearing of the Philippines fruit fly Bactrocera philippinensis

(Diptera: Tephritidae)

S.S. Resilva and G.B. Obra

Suitability of a liquid larval diet for rearing the Philippines fruit fly Bactrocera philippinensis (Diptera: Tephritidae)

S.S. Resilva, G.B. Obra and C.L. Chang

Age- and temperature-related pupal eye colour changes in various tephritid fruit fly species with a view to optimizing irradiation timing

S.S. Resilva and R. Pereira

Developing a mass-rearing system for Anastrepha fraterculus (Diptera: Tephritidae)

in north-eastern Brazil

R. Braga Sobrinho

\section{Contents continued on the inside back cover.}

The United Nations Educational, Scientific and Cultural Organization (UNESCO) has made available a grant for gratis subscriptions of this issue to 7 African university libraries: University of Nairobi (Kenya), Makerere University (Uganda), University of Ibadan (Nigeria), University of Malawi (Malawi), National University of Rwanda (Rwanda), Sokoine University of Agriculture (Tanzania) and University of Namibia (Namibia).
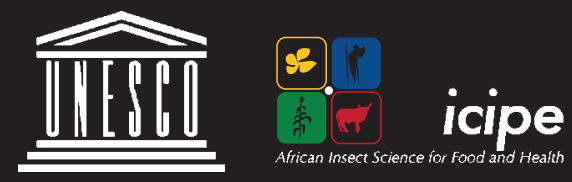

Cambridge Journals Online

For further information about this journal please go to the journal web site at: journals.cambridge.org/jti

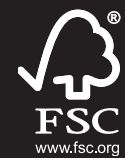

MIX
CAMBRIDGE UNIVERSITY PRESS 